\title{
Effectiveness of a stunting recovery program for children treated in a specialized center
}

\author{
Nassib B. Bueno ${ }^{1}$, Catia B. Lisboa ${ }^{1}$, Ana G. Clemente ${ }^{1}$, Renata T. Antunes ${ }^{1}$, Ana L. Sawaya ${ }^{2}$ and Telma T. Florêncio ${ }^{1}$
}

BACKGROUND: Stunting is still very prevalent in many poor and developing regions in the world. This study assessed the effectiveness of a stunting recovery program in children and its associated factors.

METHODS: The retrospective study was conducted in a center of stunting recovery. There, children stayed in a dayhospital system ( $9 \mathrm{~h}$ per day; 5 days per week), and received five meals per day, providing $80 \%$ of their energetic daily needs. The main outcome was the stunting recovery rate (i.e., the child present a height-for-age index $(\mathrm{HAZ})>-1.0$ at the time of data collection). A total of 75 children treated for at least 24 months, aged between 6 and 48 months and with an HAZ $<-2.0$ at the time of admission were included.

RESULTS: The average treatment time was 41 months. About 18 children (24.0\%) recovered from stunting. The variable "age at admission $>24$ months" (prevalence rate $(P R)=0.39,95 \%$ confidence interval $(\mathrm{Cl})$ : $0.15-0.99 ; P=0.04)$ and the variable "Household crowding index" (PR=0.65, 95\% Cl: 0.44-0.95; $P=0.03)$ were associated with the success of the treatment.

CONCLUSION: The environmental conditions in which the children live in their households and late admission to the center negatively influenced the success of stunting recovery, even with an intensive treatment.

C hildhood stunting leads to biological effects such as increased morbidity, mortality, and delayed motor and cognitive development of children (1). Furthermore, these effects reflect the social conditions of an entire population, as they continue in adulthood and cause loss of intellectual performance, work capacity, life expectancy, and reproductive outcomes of adults (2), thereby perpetuating the intergenerational cycle of poverty and malnutrition (3). Thus, linear growth is a parameter used to evaluate the quality of life of a population and is used for monitoring changes in economic and social standards (4).

Stunting is still very prevalent in many poor or developing regions in the world, such as sub-Saharan Africa, Asia, and Latin America (5). In Brazil, its prevalence is decreasing and is currently $7.2 \%$ (6). However, in some Brazilian regions, the prevalence of childhood stunting is still $>10 \%$ (7). On the outskirts of Maceió, the state of Alagoas, the site of this study, a survey conducted with children who were beneficiaries of the federal government's budget-transfer program Bolsa Familia showed a $13.4 \%$ prevalence of stunting in children younger than 60 months of age (8).

Although early infancy is the preferred moment to implement interventions to recover nutritional status of children, when such interventions are performed during childhood, the growth in terms of height can be satisfactorily resumed, thereby significantly improving the health of the child and, consequently, the society (9). Nutritionally recovered children show improvements in cognitive abilities, normalization of body composition, insulin sensitivity, levels of adipokines, and cortisol response to stressful stimuli (10-14).

The Centers for Recovery and Nutritional Education (CREN, in Portuguese) were created to minimize the effects of stunting on socially vulnerable communities. These programs are non-governmental organizations, linked to the Federal Universities of São Paulo and Alagoas, Brazil. CREN selects stunted children by conducting an active search for stunting cases in socially vulnerable communities in the areas covered by the centers and treats the most severe cases in a day-hospital model. In CREN, children receive multidisciplinary care with continuing educational assistance, five balanced meals per day, nutrition education, systematic monitoring of growth and development, and early treatment of diseases (15).

Nevertheless, the success rate of stunting recovery treatment is $\sim 32 \%$, according to the data of CREN-São Paulo (16), which is located in a region with higher socioeconomic status than the unit of Maceió-AL, where the present study was conducted. The metropolitan region of São Paulo has a Human Development Index of 0.8, whereas that of Maceió is the poorest region in the country, with a Human Development Index of $<0.7$ (17). In the analysis conducted at CRENSão Paulo, socioeconomic status of the children was not associated with the success of the treatment. Only variables related to the treatment itself, such as the length of treatment at the center, were associated with the success (16). Given the significant social and demographic differences between these

${ }^{1}$ Centro de Recuperação e Educação Nutricional, Faculdade de Nutrição, Universidade Federal de Alagoas, Cidade Universitária, Maceió, Brazil; ${ }^{2}$ Departamento de Fisiologia, Universidade Federal de São Paulo, São Paulo, Brazil. Correspondence: Nassib B. Bueno (nassib.bueno@fanut.ufal.br)

Received 8 April 2017; accepted 9 November 2017; advance online publication 17 January 2018. doi:10.1038/pr.2017.321 
two regions where these centers operate, it is likely that there are differences in the rate and determinants of treatment success between these two centers.

Thus, this study aimed to determine the rate of success of the stunting recovery program conducted at CREN-Maceió. In addition, this study sought to determine whether biological, socioeconomic, environmental, and/or clinical variables are associated with the rate of success in this particular center.

\section{METHODS}

\section{Study Design}

This is a retrospective study, which determined the rate of stunting recovery of stunted children with at least 24 months of treatment at CREN-Maceió. All analyzed data were collected once, in December 2016, from the medical records of the children.

\section{Ethical Aspects}

This study was conducted according to the guidelines laid down in the Declaration of Helsinki, and all procedures involving the children were approved by the Ethics Committee of the Federal University of Alagoas (number 468,826/2013). Parents and/or legal guardians of participating children gave informed written consent before the collection of data in the records.

\section{Setting and Participants}

Stunted children treated at CREN-Maceio from January 2012 to December 2016 were investigated in this study. The main objective of CREN-Maceió is to recover children from stunting; hence, children must present a $Z$-score of the height-for-age index (HAZ) $<-2.0$ to be admitted to the center. There are no restrictions regarding the $Z$-score of weight-for-age (WAZ) of the children at the time of admission.

The children, assisted by the day-hospital system, received five balanced meals (breakfast, collation, lunch, afternoon snack, and dinner) daily to reach $80 \%$ of their estimated energy requirements, which are calculated from the recommendation of $100 \mathrm{kcal} / \mathrm{kg}$ and $3-4 \mathrm{~g} / \mathrm{kg}$ of protein per day. The children arrive at the center at 0800 hours. and leave at 17 hours, from Monday to Friday. At the center, the children attend regular preschool classes and participate in workshops regarding hygiene, healthy eating, and others. Discharge from the center occurs when the children reach school age.

At CREN, all children are routinely assessed for signs and symptoms of disease and infections and treated appropriately by the pediatrics department of the center. On admission and annually, all children receive prophylactic treatment for iron deficiency anemia and soil-transmitted helminth infections. The families of all stunted children treated at CREN are weekly invited to participate in the activities promoted by the center, which involves professional courses and workshops regarding childcare, hygiene, self-esteem, and others.

Some inclusion criteria were adopted to obtain a more homogenous sample in the present study. To be included in this study, the children must have been treated in the day-hospital system of CREN-Maceió and should present the following characteristics: (1) age between 6 and 48 months on admission to the center; (2) $\mathrm{HAZ}<-2$ on admission to the center; (3) a minimum of 24 months of treatment in the day-hospital system of the center; and (4) be born to term. Children whose stunting was due to associated diseases, such as human immunodeficiency virus infection and cardiopathies, as diagnosed by the center pediatric service, were excluded from the present analysis.

\section{Variables}

The primary outcome was the binary variable success of the stunting recovery treatment, defined as the children presenting an $\mathrm{HAZ}>-$ 1.0, at the time of data collection (December 2016).
Bimonthly anthropometric assessments of the children in the dayhospital system are conducted at CREN. To check the length of children aged $<24$ months, a standard infantometer with $105 \mathrm{~cm}$ length and $0.1 \mathrm{~cm}$ accuracy is used. The height of children aged $>24$ months is obtained using a vertical stadiometer (measuring range, $0-200 \mathrm{~cm}$; precision, $1 \mathrm{~mm}$; Wiso, Parana, Brazil) fixed to the wall. Children below 24 months of age are weighed using a pediatric scale with a maximum capacity of $15 \mathrm{~kg}$ and accuracy of $5 \mathrm{~g}$ (Filizola, BP Baby, Campo Grande, Brazil), and for children older than 24 months, weight was measured using an anthropometric scale with maximum capacity $150 \mathrm{~kg}$ and precision of $100 \mathrm{~g}$ (Filizola, Personal, Campo Grande, Brazil). To calculate $Z$-scores, Anthro software (WHO, version 3.0.1, 2006) was used.

To explore the primary outcome, possible explanatory variables were grouped into different blocks, according to the nature of the variables and experience of the researchers. These blocks were designed as per the biological data (block 1), socioeconomic data (block 2), environmental data (block 3), and clinical data (block 4). Biological, socioeconomic, and environmental data are provided by the person responsible for the child and are routinely collected and recorded on the children's medical records by the center staff on the admission of the children at the center. Clinical data are also routinely recorded on the medical records of the children, whenever a clinical event happens or is diagnosed during the routine medical visits. All data analyzed in the study were collected from the medical records of the children, available at the center, in December 2016.

\section{Biological Data}

The biological data were sex, birth weight category $(<2500 \mathrm{~g}$ or $>2500 \mathrm{~g}$ ), breastfeeding habits, duration of treatment at the dayhospital system, age at admission, and WAZ and HAZ at admission. Birth weight information was collected from an official document, such as the child's card or birth certificate. Breastfeeding habits were categorized as $<4$ months, between 4 and 24 months, and more than 24 months. Exclusive breastfeeding is not usual in this population.

\section{Socioeconomic Data}

Information regarding the socioeconomic conditions of the families, which are routinely collected on admission by the center staff, was analyzed. These variables include referred family income per capita $\left(<\frac{1}{2}\right.$ minimum wage or $>1 / 2$ minimum wage), maternal education (Elementary level, equivalent to $\leqslant 4$ years of study; lower secondary level, equivalent to $>4$ and $<8$ years of study, and upper secondary level or higher, equivalent to $>8$ years of study), and labor situation of the mother (work outside home or not). Maternal education was verified through official certificates from educational institutions.

\section{Environmental Data}

Environmental data are derived directly from the socioeconomic conditions of families. Data on type of construction of the home (masonry or not); number of children in the household; bathroom inside the household (yes or no); floor-covering home (yes or no); public garbage collection (yes or no), public water supply (yes or no), and sewage system (yes or no) were collected. We calculated the household crowding index, defined as the total number of coresidents in the household, excluding the children, divided by the total number of rooms, excluding kitchen and bathrooms (18).

\section{Clinical Data}

The children in the day-hospital system at CREN-Maceio presenting signs and symptoms of infectious diseases are routinely assessed by the pediatric service, which has an established protocol. For this study, data on the following diagnosis of common complications were collected: respiratory disorders events, the presence of anemia, and the total number of medical events for each child during the treatment. Children diagnosed with pathological conditions during the study were adequately treated. 


\section{Stunting recovery treatment of children Articles}

\section{Statistical Analysis}

Statistical analysis was performed using SPSS software, version 20.0 (IBM, Chicago, IL). Continuous variables are presented as means and standard deviations and discrete variables as medians and interquartile ranges. Categorical variables are presented as absolute and relative frequencies. As the variable HAZ increment importantly violated normality assumptions, as tested by the Lilliefors' test, this variable was also presented as median and interquartile range. The significance of the median increase was tested using a Wilcoxon's signed-rank test.

To check the influence of several variables on the primary outcome (stunting recovery), an estimate of the prevalence ratio (PR) was calculated using Poisson regression models, with robust estimates of the variances for each variable. For multivariate analysis, we used a hierarchical model based on the previously mentioned variable blocks (biological, socioeconomic, environmental, and clinical), to avoid both multicollinearity and the inclusion of several predictors in the same model, with a small sample size (19). As the outcome studied here was the success of the treatment of stunting recovery, and not the prevalence of stunting itself, biological variables were in the hierarchical block above the socioeconomic variables. Similar previous investigations, such as those in the CREN-SP, have shown that biological variables have a greater influence than socioeconomic variables in the stunting treatment (16). As environmental variables are derived from the socioeconomic variables, it composed the third block. Finally, clinical variables, which are likely to be influenced by all variables from the other blocks, composed the fourth and last block. The statistical procedures were as follows: first, univariate analyses with each variable one at a time were conducted to quantify the unadjusted $P$ values for each association. Second, those variables in the first block (biological data) that showed an unadjusted $P$ value $<0.10$ were included in the multivariate analysis of the second block (socioeconomic data), as confounders. In turn, variables of the second block that showed an adjusted $P$ value $<0.20$ (i.e., the $P$ value obtained in the multivariate analysis including the variables from the first block with an unadjusted $P$-value $<0.20$ ) were included in the multivariate analysis of the third block. The procedure was repeated in the fourth block.

To assess mediation and/or moderation effects, variables from an inferior hierarchical block, such as the clinical variables, were added as potential confounders in a model assessing the association between a variable from a superior block, such as the environmental block, and the main outcome stunting recovery. At last, a full model, with all the variables at the same time, was estimated to check whether omitted variable bias was influencing the results. Statistical significance was determined using an $\alpha$ value of $5.0 \%$.

As a nonprobabilistic convenience sample was used, no sample size calculations were conducted a priori. A Posteriori power calculations were conducted using the G Power software (v. 3.1.9.2, Heinrich-Heine-Universität, Düsseldorf, Germany), giving the $\alpha$ value, sample size and effect size and computing achieved power.

\section{RESULTS}

Of the 104 children treated in the day-hospital system of CREN-Maceio from January 2012 to December 2016, 75 met the inclusion criteria and were analyzed in this study. The characteristics of children and their families are described in Table 1. A total of $38(50.7 \%)$ children were aged $\leqslant 24$ months at the time of admission. In general, the families were large and received less than half the minimum Brazilian wage per capita. None of the investigated mothers presented higher secondary education level, equivalent to more than 8 years of study. The living conditions were poor with regard to water supply and adequate sewage system.
Table 1. Biological, socioeconomic, environmental, and clinical characteristics of the sample $(n=75)$

\begin{tabular}{|c|c|c|}
\hline Characteristics & Mean & Standard deviation \\
\hline Age at admission (months) & 26.4 & 11.1 \\
\hline $\begin{array}{l}\text { Height-for-age at admission ( } Z \text { - } \\
\text { score) }\end{array}$ & -2.61 & 0.51 \\
\hline $\begin{array}{l}\text { Weight-for-age at admission ( } Z \text { - } \\
\text { score) }\end{array}$ & -1.48 & 0.73 \\
\hline $\begin{array}{l}\text { Increase in height-for-age during } \\
\text { treatment (Z-score) }\end{array}$ & 1.12 & 0.93 \\
\hline $\begin{array}{l}\text { Increase in weight-for-age during } \\
\text { treatment (Z-score) }\end{array}$ & 0.45 & 0.87 \\
\hline \multirow[t]{2}{*}{ Length of treatment (months) } & 41.7 & 11.9 \\
\hline & Median & Interquartile range \\
\hline Number of medical events & 26 & 23 \\
\hline Number of respiratory events & 14 & 18 \\
\hline $\begin{array}{l}\text { Number of children in the } \\
\text { household }\end{array}$ & 3 & 2 \\
\hline \multirow[t]{2}{*}{ Household crowding index } & 1.66 & 1.42 \\
\hline & Frequency & $\%$ \\
\hline Low birthweight $(<2500 \mathrm{~g})$ & 14 & 18.7 \\
\hline Female sex & 39 & 52.0 \\
\hline $\begin{array}{l}\text { Family per capita income }<1 / 2 \\
\text { minimum wage }^{a}\end{array}$ & 43 & 57.3 \\
\hline \multicolumn{3}{|l|}{ Mother education } \\
\hline Elementary level & 14 & 18.7 \\
\hline Lower secondary level & 61 & 81.3 \\
\hline Mother employed & 15 & 20.0 \\
\hline Masonry house & 54 & 72.0 \\
\hline Uncovered floor at household & 29 & 38.7 \\
\hline $\begin{array}{l}\text { Household with adequate sewage } \\
\text { system }\end{array}$ & 22 & 29.3 \\
\hline $\begin{array}{l}\text { Household with public garbage } \\
\text { collection }\end{array}$ & 69 & 92.0 \\
\hline $\begin{array}{l}\text { Household with public water } \\
\text { supply }\end{array}$ & 31 & 41.3 \\
\hline \multicolumn{3}{|l|}{ Breastfeeding } \\
\hline$<4$ months & 38 & 50.7 \\
\hline Between 4 and 24 months & 30 & 40.0 \\
\hline$>24$ months & 7 & 9.3 \\
\hline Had anemia during treatment & 24 & 32.0 \\
\hline
\end{tabular}

${ }^{a}$ Minimum wage at the time was equivalent to US\$206.85.

Eighteen children (24.0\%) recovered from stunting. (i.e., presented a HAZ $>-1.0$ in December 2016) with a mean treatment time of 41 months. All these 18 children also presented $\mathrm{WAZ}>-1.0$ at the end of the follow-up period. The median increase in HAZ was 0.82 (interquartile range $=$ $0.87 ; P<0.01)$. From the 75 included children, only $2(2.7 \%)$ showed a decrease in HAZ during the follow-up period, whereas 44 children (58.7\%) showed an increase ranging from 0 to $1.0 \mathrm{HAZ}, 14$ (18.7\%) showed an increase ranging from 1.0 


\section{Articles | Bueno et al.}

Table 2. Factors associated with the success of the stunting recovery treatment (i.e., children present a $Z$-score of height-for-age $>-1.0$ at the time of analysis; $n=75$ )

\begin{tabular}{|c|c|c|c|c|c|c|}
\hline \multirow[t]{2}{*}{ Variables } & \multicolumn{3}{|c|}{ Unadjusted analysis $^{a}$} & \multicolumn{3}{|c|}{ Adjusted analysis ${ }^{b}$} \\
\hline & PR & $95 \% \mathrm{Cl}$ & $P$ value & PR & $95 \% \mathrm{Cl}$ & $P$ value \\
\hline \multicolumn{7}{|l|}{ Block 1: Biological } \\
\hline Female sex & 0.92 & $0.41-2.06$ & 0.84 & - & - & - \\
\hline Age at admission $>24$ months & 0.39 & $0.15-0.99$ & 0.04 & - & - & - \\
\hline Low birthweight $(<2,500 \mathrm{~g})$ & 0.54 & $0.14-2.10$ & 0.37 & - & - & - \\
\hline Length of treatment (months) & 1.01 & $0.98-1.04$ & 0.24 & - & - & - \\
\hline Height-for-age at admission & 1.18 & $0.43-3.23$ & 0.74 & - & - & - \\
\hline Weight-for-age at admission & 1.36 & $0.70-2.64$ & 0.35 & - & - & - \\
\hline \multicolumn{7}{|l|}{ Breastfeeding } \\
\hline$<4$ months & 1 & - & - & - & - & \\
\hline Between 4 and 24 months & 1.56 & $0.66-3.65$ & 0.30 & - & - & - \\
\hline$>24$ months & 0.74 & $0.17-3.14$ & 0.69 & - & - & - \\
\hline \multicolumn{7}{|l|}{ Block 2: Socioeconomic ${ }^{c}$} \\
\hline Mother with elementary level of education & 0.54 & $0.14-2.10$ & 0.37 & 0.69 & $0.18-2.66$ & 0.59 \\
\hline Family per capita income $>1 / 2 \mathrm{MW}$ & 1.48 & $0.62-3.54$ & 0.36 & 1.62 & $0.70-3.73$ & 0.25 \\
\hline Mother employed & 1.56 & $0.64-3.80$ & 0.32 & 1.24 & $0.50-3.06$ & 0.64 \\
\hline \multicolumn{7}{|l|}{ Block 3: Environmental ${ }^{\mathrm{c}}$} \\
\hline Household crowding index & 0.59 & $0.37-0.93$ & 0.02 & 0.54 & $0.32-0.91$ & 0.02 \\
\hline Household with bathroom & 1.25 & $0.41-3.76$ & 0.69 & 1.38 & $0.45-4.19$ & 0.56 \\
\hline Masonry house & 1.01 & $0.41-2.48$ & 0.98 & 1.08 & $0.46-2.53$ & 0.84 \\
\hline Uncovered floor at household & 0.71 & $0.29-1.68$ & 0.43 & 0.73 & $0.31-1.69$ & 0.46 \\
\hline Household with public water supply & 1.10 & $0.48-2.53$ & 0.81 & 1.07 & $0.48-2.37$ & 0.86 \\
\hline Household with sewage system & 1.07 & $0.43-2.66$ & 0.86 & 1.11 & $0.46-2.70$ & 0.81 \\
\hline Household with public garbage collection & 1.47 & $0.23-9.27$ & 0.67 & 1.24 & $0.23-6.61$ & 0.79 \\
\hline \multicolumn{7}{|l|}{ Block 4: Clinical ${ }^{\mathrm{d}}$} \\
\hline Medical events per month & 0.83 & $0.28-2.44$ & 0.74 & 0.67 & $0.26-1.67$ & 0.39 \\
\hline Respiratory events per month & 1.23 & $0.29-5.10$ & 0.76 & 0.79 & $0.25-2.45$ & 0.68 \\
\hline Had anemia during treatment & 0.60 & $0.22-1.65$ & 0.32 & 0.55 & $0.22-1.36$ & 0.20 \\
\hline \multicolumn{7}{|c|}{$\begin{array}{l}\mathrm{Cl} \text {, confidence interval; MW, minimum wage; PR, prevalence ratio calculated using a Poisson model with robust estimate of variances. } \\
\text { aUnivariate analysis including in the model only one independent variable (each variable shown in each line) at a time, and the success of stunting recovery ( } 0=\text { no; } 1=y e s \text { ) as } \\
\text { dependent variable. } \\
\text { bMultivariate analysis including in the model as independent variables each variable shown in each line, with the addition, as covariates, of the variables from the blocks above } \\
\text { which showed a P value }<0.10 \text { in the multivariate analysis (or univariate analysis, in the case of the variables from block } 1 \text { ). } \\
\text { "For the adjusted analysis of the variables from these blocks, the variable "age at admission" was included as covariates in the models. } \\
{ }^{\mathrm{d} F o r} \text { the adjusted analysis of the variables from this block, the variables "age at admission" and "household crowding index" were included as covariates in the models. }\end{array}$} \\
\hline
\end{tabular}

to $2.0 \mathrm{HAZ}$, and 15 (20.0\%) presented an increase of 2 or more HAZ.

Table 2 shows the hierarchical analysis using Poisson regression models and the estimates of non-adjusted and adjusted PR, using the success of the stunting recovery treatment as the dependent variable. The results of the hierarchical analysis showed that the biological variable age at admission and the environmental variable household crowding index were significantly associated with the success of the treatment. The latter retained statistical significance even in the adjusted analysis (adjusted by the variables from the hierarchical block above that showed a $P$ value $<0.10$; i.e., age at admission). Children older than 24 months at admission showed a lower PR of being recovered at the time of the analysis (PR: 0.39; 95\% confidence interval (CI): $0.15-0.99, P=0.04$ ). For each increase of one unit in the household crowding index, there was a $41 \%$ decrease in the probability of stunting recovery success (PR: 0.59, 95\% CI: $0.37-0.93 ; P=0.02$ ). 


\section{Stunting recovery treatment of children Articles}

Sensitivity analyses were conducted to assess whether the significant association between the household crowding index and the success of the stunting recovery treatment was mediated by clinical variables. A new adjusted PR of this association was calculated, based on the same model shown in Table 2 (i.e., the model adjusted by age at admission), adding the number of respiratory disorders as a covariate. In this new model, the PR for household crowding index remained significant (PR: 0.65; 95\% CI: 0.44-0.96; $P=0.03$ ). Similar PR was found for the models adjusted by the number of medical consultations (data not shown). Thus, there is no evidence of mediation effects of these clinical variables in the association between household crowding index and the success of the stunting recovery treatment. Another sensitivity analysis was conducted including all variables from block 1 as covariates in the household crowding index analysis, and it still retained statistical significance (PR: 0.52; 95\% CI: $0.28-0.95 ; P=0.03$ ). Finally, when a full model, with all the variables at the same time, was estimated, only the household crowding index retained statistical significance (PR: 0.49; 95\% CI: 0.24-0.99; $P=0.04)$.

Posteriori power calculations showed that the study had an actual power of $67 \%$ to detect a significant PR of 0.59 using the predictor "household crowding index" and the binary outcome "stunting recovery." This power was achieved giving the $\alpha$ value of 5\%, the total sample size of 75 and a base rate of $15 \%$ in a mean exposure of 3.5 years (i.e., the rate of stunting recovery we would expect in this population in a controlled setting, in 3.5 years, similar to the mean treatment time in the present study).

\section{DISCUSSION}

The present study showed that the rate of success of a stunting recovery treatment of children younger than 48 months, treated in a day-hospital system at a nutritional recovery center located on the outskirts of the city of Maceió-AL, Brazil, a region with extreme social vulnerability, for at least 24 months was $24.0 \%$. It also assessed the influence of biological, socioeconomic, environmental, and clinical variables on this rate of success. Hierarchical analysis showed that only the age at admission and the household crowding index were associated with the success of the stunting recovery treatment. Children who were admitted when they were older and those living in crowded households were less likely to recover from stunting.

The likelihood of stunting recovery is considered limited if the children remain in the same restrictive environment (20). The rate of stunting recovery varies widely among studies and depends on a series of factors, such as the settings of the study and even on the cutoff points used to define recovery (21). For example, an observational investigation in a high foodinsecure Nepal area followed 529 children, aged 0-59 months at baseline, for 30 months and reported an increase in stunting levels from 66 to $76.5 \%$ (22). On the other hand, a study from a Peruvian cohort of 2,052 children, aged 618 months at baseline, followed up for $\sim 4$ years, reported that from the 380 stunted children $(\mathrm{HAZ}<-2.0)$ at baseline, 140 $(36.8 \%)$ were not stunted $(\mathrm{HAZ}>-2.0)$ in the second assessment (23). A cohort study conducted in Uganda with 366 stunted children followed for 2 years showed that the stunting recovery rate was $\sim 20 \%$ (24). A study conducted in a Jamaican treatment center, reporting the recovery of length in 368 severely malnourished children, showed that only 23 (6.2\%) increased HAZ by at least 0.75 during treatment (25). It is noteworthy that if the cutoff point used to indicate stunting recovery in the present study was $\mathrm{HAZ}>-2.0,52$ out of the 75 studied children (69.3\%) would be considered recovered.

Nevertheless, we used a more conservative approach that allowed the comparison with CREN-SP, which showed a recovery rate of $32 \%$ (16). In addition, the poorer setting that the children from CREN-Maceió are inserted was also considered in the selection of this conservative cutoff point. Previous studies of our research group, using a shorter followup period, have already shown that the treatment used at CREN is able to induce catch-up growth, at least to some extent (26). Nevertheless, in adverse conditions, such as those of the children studied here, to show catch-up growth only, or to show an HAZ $>-2$, may not be enough to discharge the children and send them back to their home environment since their nutritional status could rapidly deteriorate again. Considering that the children from CREN-Maceió are inserted in a poorer setting, we believe that the rate of recovery found in the present study is within the expected range.

The household crowding index was negatively associated with stunting recovery. Household overcrowding has been strongly associated with higher incidence of infections in children, especially those of the respiratory tract (27) and diarrhea (28), which could severely compromise the stunting recovery treatment. However, in the present study, sensitivity analyses did not show any effect of mediation by the clinical variables, including episodes of respiratory infections, on the association between the household crowding index and treatment success. It is possible that the association noted here is related to other negative aspects of household overcrowding, such as a decrease in the maternal responsiveness to their children (29). In addition, surveys conducted in cities in the Brazilian Northeast also show that household overcrowding is related to increased food insecurity at home, which could halt the stunting recovery of the children (30). Both maternal responsiveness and household food insecurity, which were not investigated in the present study, could mediate the effects of crowding on the failure of stunting recovery here evidenced.

Fernandes et al. (16) conducted a study of 15 years at the CREN-São Paulo to determine the variables that were associated with the likelihood of recovery of stunting in children at discharge. In accordance to the data shown here, these authors found an influence of the admission age, where children aged $>24$ months were less likely to successfully achieve stunting recovery. Considering that the first 24 months 


\section{Articles $\mid$ Bueno et al.}

of life are a critical stage of development, where the child's body is more susceptible to the effects of nutritional interventions (9), it is expected that children in this age group present higher success rate of stunting recovery.

It is important to point out that the conditions in which the children live outside the center may play a key role in the success of the stunting recovery treatment. The children studied here spent 5 days per week and $9 \mathrm{~h}$ per day in the dayhospital system and spent the remaining time at home, living with families that reside in urban peripheral areas with high social vulnerability, sanitation problems, and with mothers with low education who are not placed in the labor market. In the literature, low maternal education is associated with inadequate practices of childcare, such as a reduced ability of food choice in a healthy eating context, which may lead to greater probability of children presenting with stunting (31). However, none of these variables showed a significant association with treatment success, which can be explained by the fact that, in general, all the families were in the same large context of social vulnerability and, possibly, the nuances differentiating a family from the other were not large enough, making it difficult to identify associative patterns.

Low birth weight is a sensitive fetal health indicator and is commonly associated with malnutrition. However, this variable had no significant effect on the success of the stunting recovery treatment. It is possible that the stunting in the children studied here was mainly due to postnatal insults resulting from their precarious living conditions instead of intrauterine insults (32). It is common that in underdeveloped and developing countries, mean HAZ at birth is adequate, but begins to falter thereafter (33). Finally, although the association between malnutrition and infection is already well documented (34), in this study, no association was noted between the incidence of infectious diseases and the success of the stunting recovery treatment. It is possible that because all children are monitored daily and treated immediately after diagnosis of an infection, the impact of infections on the nutritional recovery treatment was reduced.

The present study has some limitations. First, the retrospective aspect of the study weakens its conclusions. Second, the small sample size may explain the lack of significance in some variables investigated. Owing to the nature of the study, it was only possible to use a non-probabilistic, convenience sampling approach, which gives the study an exploratory character. In addition, the sample was homogenous regarding some socioeconomic variables, such as mother's level of schooling, making it difficult to identify associative patterns.

In conclusion, the rate of stunting recovery at CRENMaceió was within the range reported in other interventions. Although most of the socioeconomic, environmental, and clinical variables did not show a significant association, possibly due to the high intensity of treatment in CREN, household crowding index was inversely associated with stunting recovery. Furthermore, children who were admitted to the center when they were younger than 24 months also showed higher rates of stunting recovery, reinforcing that the treatment of stunted children must begin early. Thus, poor environmental conditions have a negative effect on the stunting recovery of children in high social vulnerability, even in a setting of a high-intensity, day-hospital system, treatment. This indicates that public health policies should take into account the possibility of providing better housing conditions for the poorest population and should strive to identify cases of stunting before the age of 2 years, by conducting, e.g., home visits in poorer locations.

Disclosure: This research received no specific grant from any funding agency, commercial or not-for-profit sectors. The authors declare no conflict of interest.

\section{REFERENCES}

1. Black RE, Victora CG, Walker SP, et al. Maternal and child undernutrition and overweight in low-income and middle-income countries. Lancet 2013;382:427-51.

2. Victora CG, Adair L, Fall C, et al. Maternal and child undernutrition: consequences for adult health and human capital. Lancet 2008;371: 340-57.

3. Aizer A, Currie J. The intergenerational transmission of inequality: maternal disadvantage and health at birth. Science 2014;344:856-61.

4. Hoddinott J, Behrman JR, Maluccio JA, et al. Adult consequences of growth failure in early childhood. Am J Clin Nutr 2013;98:1170.

5. De Onis M, Blössner M, Borghi E. Prevalence and trends of stunting among pre-school children, 1990-2020. Public Health Nutr 2012;15:142-8.

6. Conde WL, Monteiro CA. Nutrition transition and double burden of undernutrition and excess of weight in Brazil. Am J Clin Nutr 2014;100: 1617S-22S

7. Ferreira HS, Cesar JA, Assunção ML, et al. Time trends (1992-2005) in undernutrition and obesity among children under five years of age in Alagoas State, Brazil. Cad Saúde Pública 2013;29:793-800.

8. Cabral MJ, Vieira KA, Sawaya AL, et al. Perfil socioeconômico, nutricional e de ingestão alimentar de beneficiários do Programa Bolsa Família. Estud Av 2013;27:71-87.

9. Adair LS, Fall CH, Osmond C, et al. Associations of linear growth and relative weight gain during early life with adult health and human capital in countries of low and middle income: findings from five birth cohort studies. Lancet 2013;382:525-34.

10. Gandhi M, Ashorn P, Maleta K, et al. Height gain during early childhood is an important predictor of schooling and mathematics ability outcomes. Acta Paediatr 2011;100:1113-8.

11. Martins VJ, Martins PA, Neves Jd, et al. Children recovered from malnutrition exhibit normal insulin production and sensitivity. Br J Nutr 2008;99:297-302.

12. Martins VJ, Neves AP, Franco Mdo C, et al. Impact of nutritional recovery with linear growth on the concentrations of adipokines in undernourished children living in Brazilian slums. Br J Nutr 2014;112: 937-44.

13. Martins VJ, Neves AP, Garcia MC, et al. Normal cortisol response to cold pressor test, but lower free thyroxine, after recovery from undernutrition. Br J Nutr 2016;115:14-23.

14. Das Neves J, Martins PA, Sesso R, et al. Children treated in day-hospital or outpatient clinic exhibit linear catch-up and normal body composition. J Nutr 2006;136:648-55.

15. Vieira MF, Ferraro AA, Souza MH, et al. Height and weight gains in a nutrition rehabilitation day-care service. Public Health Nutr 2010;13: 1505-10.

16. Fernandes MB, López RV, Albuquerque MP, et al. A 15-year study on the treatment of undernourished children at a nutrition rehabilitation centre (CREN), Brazil. Public Health Nutr 2012;15:1108-16.

17. Brazilian Atlas of Human Development Ranking-Todas as regiões metropolitanas. 2010 (accessed May 2016) http://www.atlasbrasil.org.br/ 2013/en/. 
18. Melki IS, Beydoun HA, Khogali M, Tamim H, Yunis KA. National Collaborative Perinatal Neonatal Network (NCPNN). Household crowding index: a correlate of socioeconomic status and inter-pregnancy spacing in an urban setting. J Epidemiol Community Health 2004;58:476-80.

19. Victora CG, Huttly SR, Fuchs SC, et al. The role of conceptual frameworks in epidemiological analysis: a hierarchical approach. Int J Epidemiol 1997;26:224-7.

20. De Onis M. Commentary: socioeconomic inequalities and child growth. Int J Epidemiol 2003;32:503-5.

21. Golden MH. Is complete catch-up possible for stunted malnourished children? Eur J Clin Nutr 1994;48:S58-70.

22. Busert LK, Neuman M, Rehfuess EA, et al. Dietary diversity is positively associated with deviation from expected height in rural Nepal. J Nutr 2016;146:1387-93.

23. Crookston BT, Penny ME, Alder SC, et al. Children who recover from early stunting and children who are not stunted demonstrate similar levels of cognition. J Nutr 2010;140:1996-2001.

24. Vella V, Tomkins A, Borghesi A, et al. Determinants of stunting and recovery from stunting in northwest Uganda. Int J Epidemiol 1994;23: 782-6.

25. Walker SP, Golden MH. Growth in length of children recovering from severe malnutrition. Eur J Clin Nutr 1988;42:395-404.

26. Alves JF, Britto RP, Ferreira HS, Sawaya AL, Florêncio TM. Evolution of the biochemical profile of children treated or undergoing treatment for moderate or severe stunting: consequences of metabolic programming? J Pediatr (Rio J) 2014;90:356-62.
27. Murray EL, Klein M, Brondi L, et al. Rainfall, household crowding, and acute respiratory infections in the tropics. Epidemiol Infect 2012;140: 78-86.

28. Baker MG, McDonald A, Zhang J, et al. Infectious diseases attributable to household crowding in New Zealand: a systematic review and burden of disease estimate, Wellington: He Kainga Oranga/Housing and Health Research Programme, University of Otago, 2013. Available at: http:// www.healthyhousing.org.nz/wp-content/uploads/2010/01/HH-CrowdingID-Burden-25-May-2013.pdf. (last accessed 24 September 2016.

29. Evans GW, Ricciuti HN, Hope S, et al. Crowding and cognitive development: the mediating role of maternal responsiveness among 36month-old children. Environ Behav 2010;42:135-48.

30. Facchini LA, Nunes BP, Motta JV, et al. Food insecurity in the Northeast and South of Brazil: magnitude, associated factors, and per capita income patterns for reducing inequities. Cad Saúde Pública 2014;30:161-74.

31. Pongou R, Salomon JA, Ezzati M. Health impacts of macroeconomic crises and policies: determinants of variation in childhood malnutrition trends in Cameroon. Int J Epidemiol 2006;35:648-56.

32. Gluckman PD, Hanson MA, Buklijas T. A conceptual framework for the developmental origins of health and disease. J Dev Orig Health Dis 2010;1:16-8.

33. Shrimpton R, Victora C, de Onis M, et al. Worldwide timing of growth faltering: implications for nutritional interventions. Pediatrics 2001;107:E75.

34. Rodríguez L, Cervantes E, Ortiz R. Malnutrition and gastrointestinal and respiratory infections in children: a public health problem. Int J Environ Res Public Health 2001;8:1174-205. 